Acta Crystallographica Section F

Structural Biology

and Crystallization

Communications

ISSN 1744-3091

\section{Response to Detection and analysis of unusual features in the structural model and structure-factor data of a birch pollen allergen}

The authors of J. Immunol. 184, 725-735 respond to the article by Rupp (2012), Acta Cryst. F68, 366-376.

On 9 February 2012, the Editors of Acta Crystallographica Section F contacted the authors of a paper published in J. Immunol. in 2010 (Zaborsky et al., 2010) concerning a manuscript received for publication on 12 January 2012 (Rupp, 2012). This manuscript presents strong evidence that the diffraction data of Bet $\mathrm{v} 1 \mathrm{~d}$ (PDB code $3 \mathrm{k} 78$; published in the J. Immunol. paper) are not derived from a diffraction experiment and that the model of $3 \mathrm{k} 78$ contains some highly improbable features.

The University of Salzburg immediately informed and commissioned the Austrian Agency for Research Integrity (OeAWI) to carry out an investigation into possible data fraud on the part of author Robert Schwarzenbacher, the co-author solely responsible for the Bet v 1d structure and the crystallographic section of the J. Immunol. paper. The OeAWI is presently preparing a report of this investigation.

Author Schwarzenbacher admits to the allegations of data fabrication and deeply apologizes to the co-authors and the scientific community for all the problems this has caused. The Protein Data Bank has been informed and has been asked to retract the $3 \mathrm{k} 78$ entry, which was obsoleted in February 2012. The main body of the J. Immunol. publication concerns the immunological study and the retraction of the crystallographic section does not affect the major conclusions. The Editors of J. Immunol. have been informed about the problem with the structure 3k78. Co-authors Zaborsky, Brunner, Wallner, Himly, Karl, Ferreira and Achatz were in no way involved in the generation of the crystallographic data.

Note added in proof: subsequent to the acceptance of this article for publication, author Schwarzenbacher withdrew his admission of the allegations.

\section{References}

Rupp, B. (2012). Acta Cryst. F68, 366-376.

Zaborsky, N., Brunner, M., Wallner, M., Himly, M., Karl, T., Schwarzenbacher, R., Ferreira, F. \& Achatz, G. (2010). J. Immunol. 184, 725-735. 